Article

\title{
Investigation on the Enhanced Oxidation of Ferritic/Martensitic Steel P92 in Pure Steam
}

\section{Juntao Yuan ${ }^{1,2}$, Ximao Wu ${ }^{3}$, Wen Wang ${ }^{1, *}$, Shenglong Zhu ${ }^{1}$ and Fuhui Wang ${ }^{1}$}

1 State Key Laboratory for Corrosion and Protection, Institute of Metal Research, Chinese Academy of Sciences, Shenyang 110016, Liaoning, China; E-Mails: jtyuan@alum.imr.ac.cn (J.Y.); slzhu@imr.ac.cn (S.Z.); fhwang@imr.ac.cn (F.W.)

2 Tubular Goods Research Institute of China National Petroleum Corporation, Xi' an 710077, Shaanxi, China

3 State Grid Liaoning Electric Power Research Institute, Shenyang 110006, Liaoning, China; E-Mail:wuximao69@163.com

* Author to whom correspondence should be addressed; E-Mail: wen@imr.ac.cn; Tel.: +86-024-2390-4856; Fax: +86-024-2389-3624.

Received: 17 December 2013; in revised form: 23 January 2014 / Accepted: 25 March 2014 / Published: 3 April 2014

\begin{abstract}
Oxidation of ferritic/martensitic steel P92 was investigated in pure oxygen and in pure steam at $600-800{ }^{\circ} \mathrm{C}$ by thermogravimetric analysis (TGA), optical microscopy (OM), scanning electron microscopy (SEM), and X-ray diffraction (XRD). The results showed that the oxidation of P92 was significantly enhanced and multilayer scale with an outer iron oxides layer formed in pure steam. At $700{ }^{\circ} \mathrm{C}$, the gas switch markedly influenced the scaling kinetics and scale microstructure. It was supposed that the higher affinity of iron to steam would be attributed to the enhanced oxidation of P92 in pure steam, and the much easier transport of hydroxyl would account for the significant difference induced by gas switch.
\end{abstract}

Keywords: $\mathrm{Fe}-\mathrm{Cr}$ alloys; high temperature oxidation; steam oxidation; TGA

\section{Introduction}

In recent years, the effect of water vapor on the oxidation of $\mathrm{Fe}-\mathrm{Cr}$ alloys has been studied extensively. It is indicated that addition of water vapor to oxidizing gas would significantly enhance the oxidation rate 
of $\mathrm{Fe}-\mathrm{Cr}$ alloys with mediate $\mathrm{Cr}$ content compared to that in dry gas and result in rather different scale structure [1]. The primary reason is that water vapor causes the transformation of protective Cr-rich oxide scales into non-protective Fe-rich oxide scales, termed as "breakaway oxidation" [2-4]. Chromium evaporation in terms of $\mathrm{CrO}_{2}(\mathrm{OH})_{2}$ has been preferably applied to interpret the breakaway of protective chromia scale in water vapor containing environments, especially in wet oxygen [5-7]. However, chromium evaporation in low-oxygen-level environments (e.g., pure steam) would be neglected since the formation of volatile $\mathrm{CrO}_{2}(\mathrm{OH})_{2}$ needs the participation of oxygen [8,9]. In pure steam environment, breakaway oxidation was also observed in our previous work [10]. In this perspective, the breakaway of protective chromia scale might be attributed to the local failure like cracking [4].

Oxidation of $10 \% \mathrm{Cr}$ steels showed a slightly different behavior. After oxidation in dry gases, a thin protective scale was formed. In wet gases, multilayer oxides consisting of an outward-growing iron oxides layer and inward-growing $\mathrm{Fe}-\mathrm{Cr}$ oxides layer always form even after short-term exposure [11]. Breakaway oxidation phenomenon has not been observed in the scaling kinetics. This suggests a rather different initial oxidation mechanism from the breakaway oxidation; however, it is still open to debate.

Automatic recording balance make it possible to get a continuous record of the reaction kinetics and, in this way, many details come to light that are hidden by other methods [12]. The present work obtained the short-term continuous oxidation kinetics of ferritic/martensitic steel P92 by introducing pure steam into Thermogravimetric Analysis (TGA) system, and investigated the microstructure and chemical compositions of oxide scales by Optical Microscopy (OM), Scanning Electron Microscopy (SEM), Energy Dispersive Spectrometer (EDS), and X-ray Diffraction (XRD). The effect of gas switch on the oxidation behavior was also investigated by TGA to reveal the influence of water steam on the scale growth rate of P92 in situ. Based on the results, the mechanism of steam oxidation was discussed.

\section{Results}

\subsection{Oxidation in Pure Oxygen}

Figure 1 shows the oxidation kinetics of P92 exposed to pure oxygen at $600-800{ }^{\circ} \mathrm{C}$. It is evident that oxidation kinetics is temperature-dependent. Mass gains are significantly increasing with temperature elevated. At 600 and $700{ }^{\circ} \mathrm{C}$, the mass gains are extremely small and the oxidation kinetics follows the near-parabolic rate regime. At $800{ }^{\circ} \mathrm{C}$, breakaway kinetics can be seen after the initial relatively slow scaling stage. Oxidation kinetics were modeled using parabolic rate law as described as $(\Delta \mathrm{W} / \mathrm{A})^{2}=\mathrm{k}_{\mathrm{p}} \cdot t$, where $(\Delta \mathrm{W} / \mathrm{A})$ is the mass gain $\left(\mathrm{mg} / \mathrm{cm}^{2}\right), \mathrm{k}_{\mathrm{p}}$ is the parabolic rate constant $\left(\mathrm{mg}^{2} / \mathrm{cm}^{4} / \mathrm{h}\right)$ and $t$ is the exposure time (h). All the parabolic rate constants are summarized in Table 1.

Surface morphology of P92 after 24 h oxidation in pure oxygen was dependent on temperature as revealed in oxidation kinetics. At low temperatures $\left(600\right.$ and $\left.700{ }^{\circ} \mathrm{C}\right)$, relatively flat oxide scale with visible grinding marks and few Fe-rich nodules can be seen. As temperature rose up to $800{ }^{\circ} \mathrm{C}$, large Fe-rich nodules became predominant, which was in accordance with the much greater scaling rate as suggested in oxidation kinetics. Figure $2 \mathrm{a}-\mathrm{c}$ presents the morphologies of flat scales formed at studied temperatures. There is evidence that the flat scale thickened (because the grinding marks in the flat scale region disappeared gradually) as temperature rose and oxide ridges can be clearly seen at $800{ }^{\circ} \mathrm{C}$. The morphology of oxide nodules formed at $800{ }^{\circ} \mathrm{C}$ is shown in Figure $2 \mathrm{~d}$, and indicates that it is covered by porous iron oxides. 
Figure 1. Oxidation kinetics of P92 steel in pure oxygen.

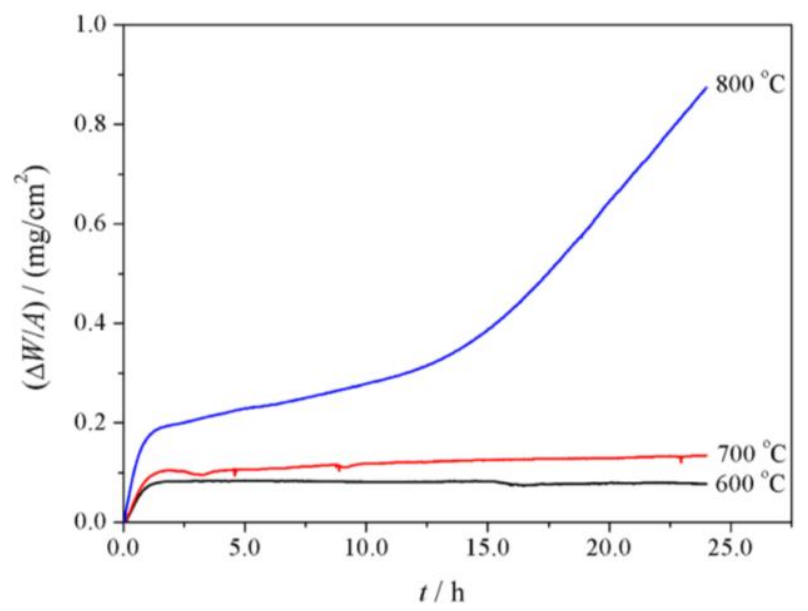

Table 1. Summary of parabolic rate constants.

\begin{tabular}{|c|c|c|}
\hline$T /{ }^{\circ} \mathbf{C}$ & $k_{p}($ steam $) /\left(\mathrm{mg}^{2} \cdot \mathrm{cm}^{-4} \cdot h\right)$ & $\mathrm{k}_{\mathrm{p}}($ oxygen $) /\left(\mathrm{mg}^{2} \cdot \mathrm{cm}^{-4} \cdot \mathrm{h}\right)$ \\
\hline 600 & 0.11 & - \\
\hline 700 & 1.70 & $3.67 \times 10^{-4}$ \\
\hline 800 & 4.46 & $5.40 \times 10^{-3}, 7.88 \times 10^{-2}$ \\
\hline
\end{tabular}

Figure 2. Surface morphologies of the flat scales formed on $\mathrm{P} 92$ after 24 h oxidation in pure oxygen at (a) $600{ }^{\circ} \mathrm{C}$; (b) $700{ }^{\circ} \mathrm{C}$; and (c) $800{ }^{\circ} \mathrm{C}$; (d) Top-view image of surface nodules formed in pure oxygen at $800{ }^{\circ} \mathrm{C}$.

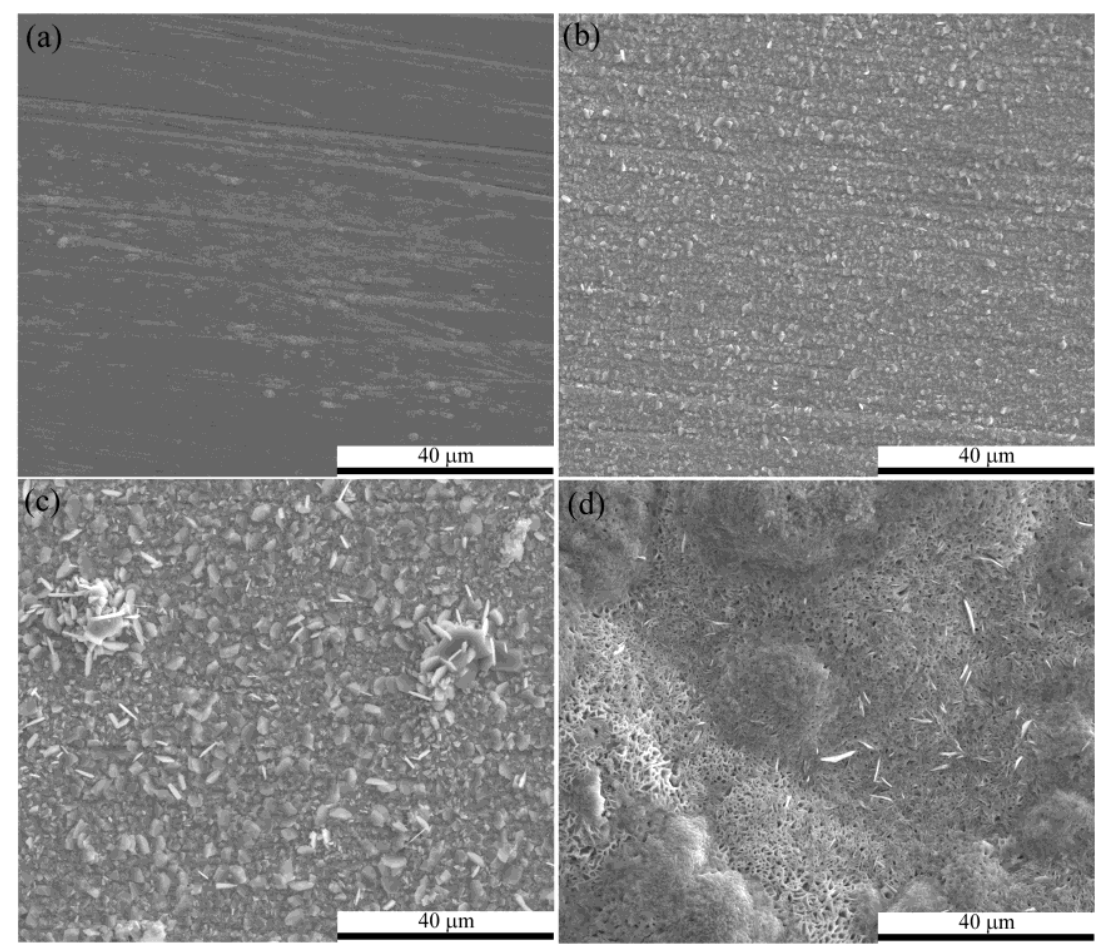

Figure 3 displays the GIXRD patterns of $\mathrm{P} 92$ after $24 \mathrm{~h}$ oxidation in pure oxygen. At all temperatures, the oxide scale was composed of corundum-type oxides, noted as $(\mathrm{Fe}, \mathrm{Cr})_{2} \mathrm{O}_{3}$. The diffraction peaks were close to standard peaks of $\mathrm{Cr}_{2} \mathrm{O}_{3}$ at low temperatures, while they were near to standard peaks of $\alpha-\mathrm{Fe}_{2} \mathrm{O}_{3}$ at $800{ }^{\circ} \mathrm{C}$. At $800{ }^{\circ} \mathrm{C}$, little amount of spinel oxides were also detected. 
Figure 3. Grazing Incidence XRD (GIXRD) patterns of surface oxide scales formed on P92 after $24 \mathrm{~h}$ oxidation in pure oxygen.

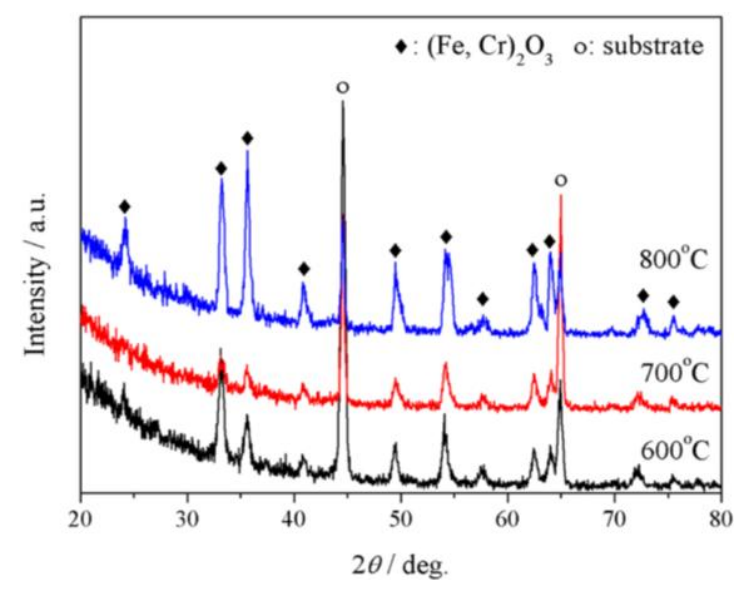

The cross section morphologies also showed the temperature dependence. Figure 4 presents the cross section morphologies at 600 and $800{ }^{\circ} \mathrm{C}$, element distribution profile is also given there. The oxide scale grown at $600{ }^{\circ} \mathrm{C}$ (Figure 4a) was extremely thin, and few small iron-containing nodules can be seen. There was evidence that the oxide scale formed at $800{ }^{\circ} \mathrm{C}$ was embedded with large protruding nodules and concave craters. The base scale grown at $800{ }^{\circ} \mathrm{C}$ is shown in Figure $4 \mathrm{~b}$, which was thicker in some extent compared to that at $600{ }^{\circ} \mathrm{C}$ and mainly consisted of (Cr,Mn) oxides. The large oxide nodules formed at $800{ }^{\circ} \mathrm{C}$ is present in Figure 4c. The EDS result (Figure 4d) indicates that the protruding nodules were iron oxides while the concave craters were composed of $(\mathrm{Fe}, \mathrm{Cr}, \mathrm{Mn})$ oxides. It is interesting that there were thin $\mathrm{Cr}$-rich layers at nodule/crater and crater/substrate interfaces. It would be reasonable to consider the protruding nodules as $\mathrm{Fe}_{2} \mathrm{O}_{3}$, the thin base scale as $\mathrm{Cr}_{2} \mathrm{O}_{3}$, and the concave craters as $(\mathrm{Fe}, \mathrm{Cr}, \mathrm{Mn})_{3} \mathrm{O}_{4}$.

Figure 4. Cross section morphologies of base oxide scales formed on P92 after 24 h oxidation in pure oxygen at (a) $600{ }^{\circ} \mathrm{C}$; and (b) $800{ }^{\circ} \mathrm{C}$; (c) Cross section image of oxide nodules formed at $800{ }^{\circ} \mathrm{C}$; and (d) chemical composition distribution along the line indicated in (c).
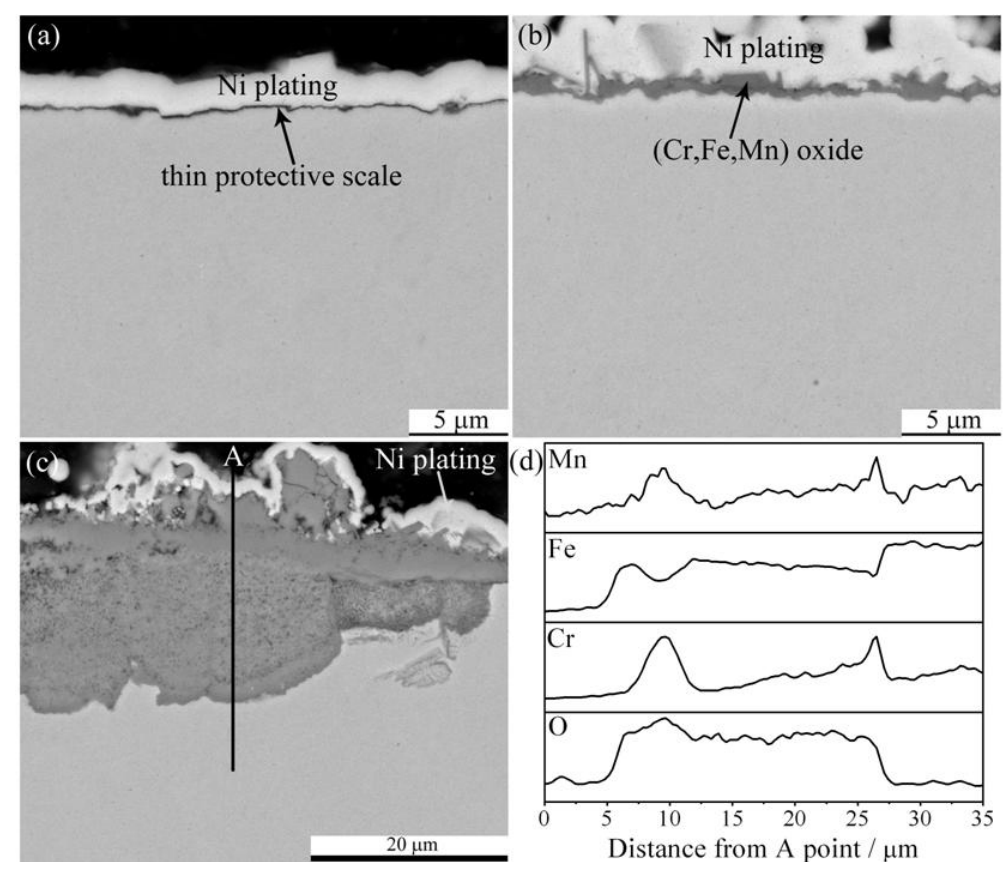


\subsection{Oxidation in Pure Steam}

Figure 5 shows the oxidation kinetics of P92 in pure steam. It is clear that the mass gains in pure steam at a given temperature were approximately 20-40 times than those in oxygen. As temperature increased, the oxidation rate was significantly enhanced. In order to examine the kinetics regime, the time exponent of power function described as $(\Delta \mathrm{W} / \mathrm{A})=\mathrm{k} \cdot t^{n}$ were determined by plotting $\ln (\Delta \mathrm{W} / \mathrm{A}) \sim \ln t$. The time exponents were $0.42,0.49$ and 0.38 for $600-800{ }^{\circ} \mathrm{C}$ respectively, suggesting that the scaling rate regime was near-parabolic. The parabolic rate constants are also given in Table 1 . It is indicated that the oxidation rate of $\mathrm{P} 92$ in pure steam at a given temperature was several orders of magnitude greater than that in oxygen. In pure steam, the temperature-dependence of parabolic rate constants were modeled using Arrhenius equation, and the apparent activation energy was determined as $147.9 \mathrm{~kJ} / \mathrm{mol}$. This value was consistent to the oxidation activation energy of $\mathrm{T} 91 \mathrm{in} \mathrm{Ar}+10 \% \mathrm{H}_{2} \mathrm{O}$ at $600-700{ }^{\circ} \mathrm{C}$ [13].

Figure 5. Oxidation kinetics of P92 steel in pure steam.

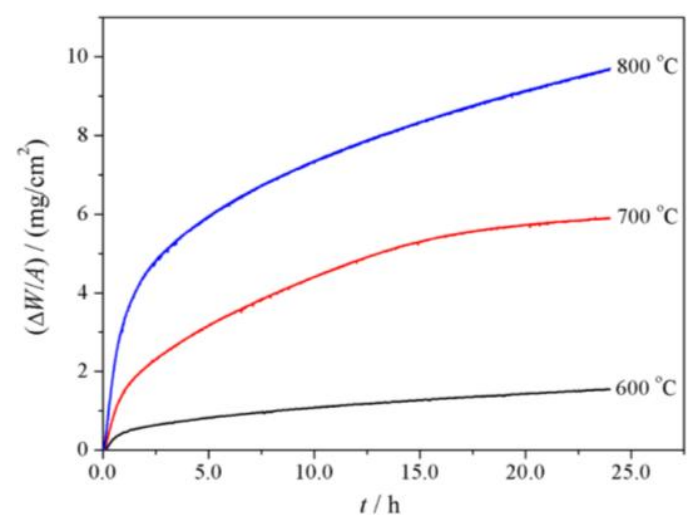

The outermost oxide scales formed on P92 after $24 \mathrm{~h}$ oxidation in pure steam were identified by GIXRD technology. Figure 6a presents the GIXRD patterns. It is suggested that the outer scales grown at 600 and $700{ }^{\circ} \mathrm{C}$ were composed of $\mathrm{Fe}_{2} \mathrm{O}_{3}$ and spinel oxides possibly as $\mathrm{Fe}_{3} \mathrm{O}_{4}$ and/or $(\mathrm{Fe}, \mathrm{Cr})_{3} \mathrm{O}_{4}$. At $800{ }^{\circ} \mathrm{C}$, the exclusive diffraction peaks of spinel oxides at the position $2 \theta=30.1^{\circ}, 43.1^{\circ}$ and $57.1^{\circ}$ disappeared, indicating the absence of spinel oxides in the outer scale. Figure $6 \mathrm{~b}$ shows the XRD patterns detected using X-ray with upright incidence angle. It can be seen that the diffraction patterns were very similar to GIXRD patterns, except that little amount of spinel oxides were detected at $800{ }^{\circ} \mathrm{C}$.

Figure 6. (a) GIXRD (incidence angle $=0.5^{\circ}$ ) patterns of the outermost surface oxides; and (b) XRD patterns of the outer surface oxides formed on P92 after $24 \mathrm{~h}$ oxidation in pure steam.
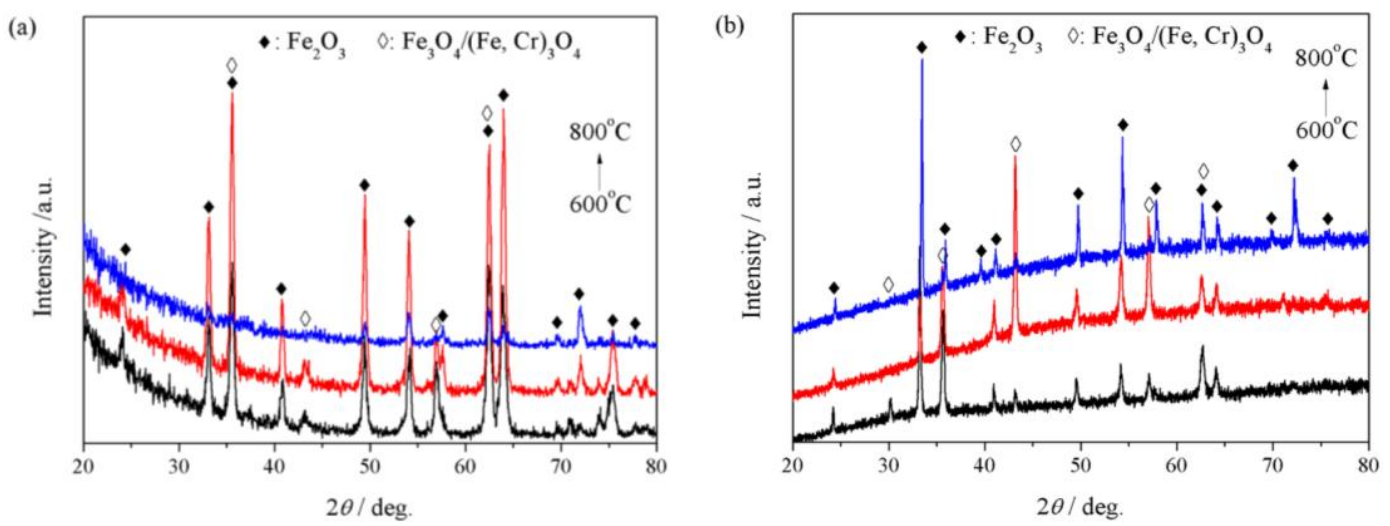
Investigating the surface morphologies after $24 \mathrm{~h}$ exposure in pure steam by SEM, we found several characteristics. First, considerable exfoliation was observed at 600 and $700{ }^{\circ} \mathrm{C}$, while only cracks were observed at $800{ }^{\circ} \mathrm{C}$. Second, surface morphologies of outer scales varied with exposure temperature. As temperature increased, oxide whiskers were suppressed, as indicated in Figure 7a-c. A plenty of pores can be seen in the top-view images after the exfoliation of outer scale, as shown in Figure 7d. As revealed by GIXRD patterns, the outermost scale could be considered as $\mathrm{Fe}_{2} \mathrm{O}_{3}$, the sub-scale as $\mathrm{Fe}_{3} \mathrm{O}_{4}$.

Figure 7. Surface morphologies of oxide scales formed on $\mathrm{P} 92$ after $24 \mathrm{~h}$ oxidation in pure steam at (a) $600{ }^{\circ} \mathrm{C}$; (b) $700{ }^{\circ} \mathrm{C}$; and (c) $800{ }^{\circ} \mathrm{C}$; (d) showing the morphology of sub-scale after exfoliation of outer oxides at $600{ }^{\circ} \mathrm{C}$.

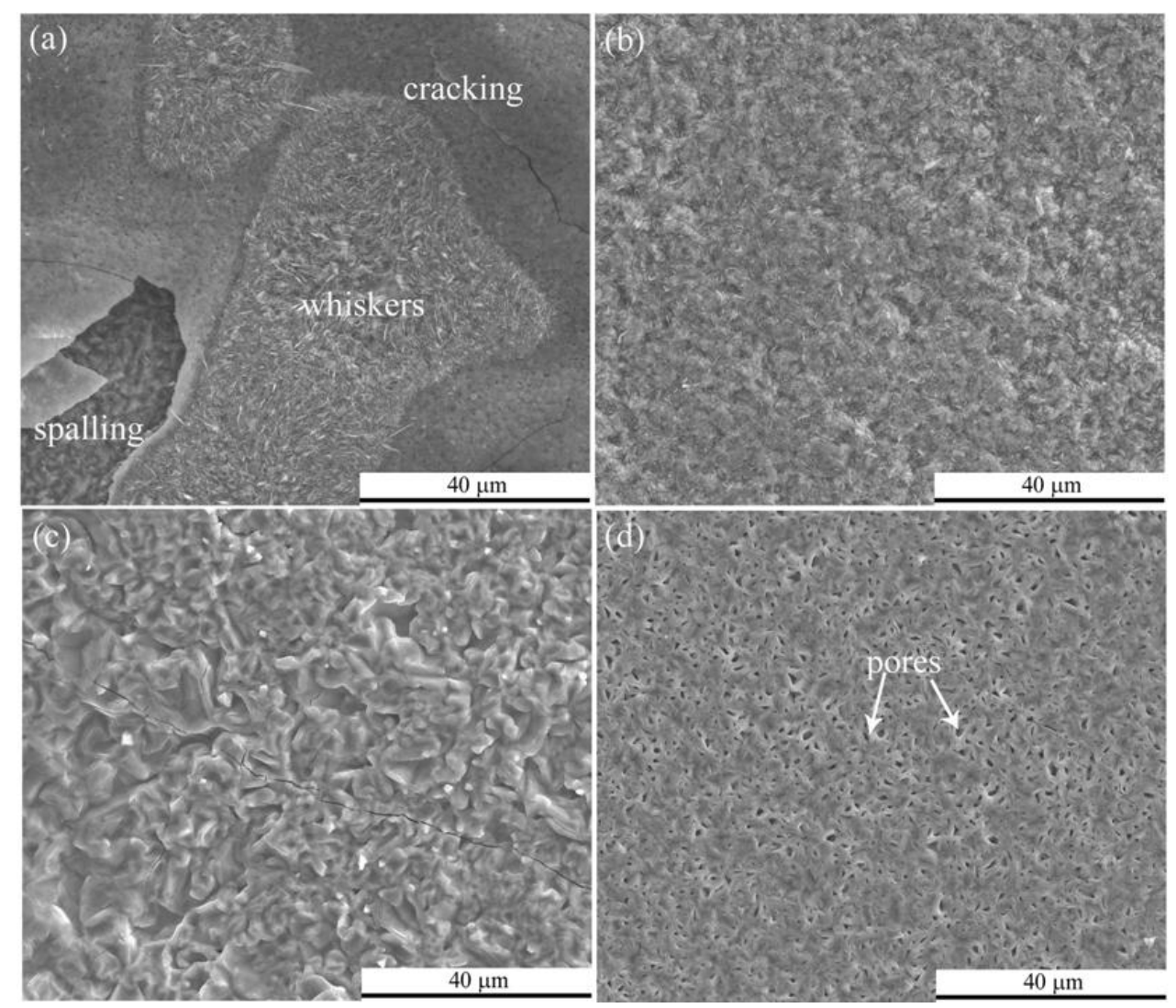

Cross section morphologies of P92 after 24 h exposure in pure steam are shown in Figure $8 \mathrm{a}-\mathrm{c}$. At all temperatures, double-layer oxide scales were observed. The outer layer was somewhat thicker than the inner layer at $600{ }^{\circ} \mathrm{C}$, while the thickness of these two layers tended to be equal as temperature rose up to $800{ }^{\circ} \mathrm{C}$. Element distribution profile by EDS indicated that the outer layer was iron oxides while the inner scale was $(\mathrm{Fe}, \mathrm{Cr}, \mathrm{Mn})$ oxides in all cases. Figure 8d shows the EDS line scan through the scale formed at $800{ }^{\circ} \mathrm{C}$. It is noted that there was enrichment of $\mathrm{Cr}$ in the region near the interface between the inner layer and substrate.

\subsection{Oxidation by Switching Gas at Interval}

Figure 9a shows mass gain data of P92 during isothermal oxidation at $700{ }^{\circ} \mathrm{C}$ with in situ gas switching (from pure steam to pure oxygen, or contrarily) every $5 \mathrm{~h}$ without intermediate cooling. In the "oxygen then steam" case, once oxygen was switched by steam, oxidation kinetics suddenly increased to 
a great extent. While in the "steam then oxygen" case, the oxidation rate was significantly decelerated when steam was switched by oxygen. Modeling the oxidation kinetics by parabolic law, the parabolic rate constants were taken from the parabolic plot as shown in Figure 9b. During the first oxidation stage, the bulk P92 showed similar parabolic rate constants as described in Table 1. But after gas switching, the rate constants were rather different. For the oxidation in pure steam, the rate constant in the second stage was slightly lower than that in the first stage. While for the oxidation in pure oxygen, the rate constant in the second stage was rather greater than that in the first stage.

Figure 8. Cross section morphologies of base oxide scales formed on P92 after $24 \mathrm{~h}$ oxidation in pure steam at (a) $600{ }^{\circ} \mathrm{C}$; (b) $700{ }^{\circ} \mathrm{C}$; and (c) $800{ }^{\circ} \mathrm{C}$; and (d) chemical composition distribution along the line indicated in (c).
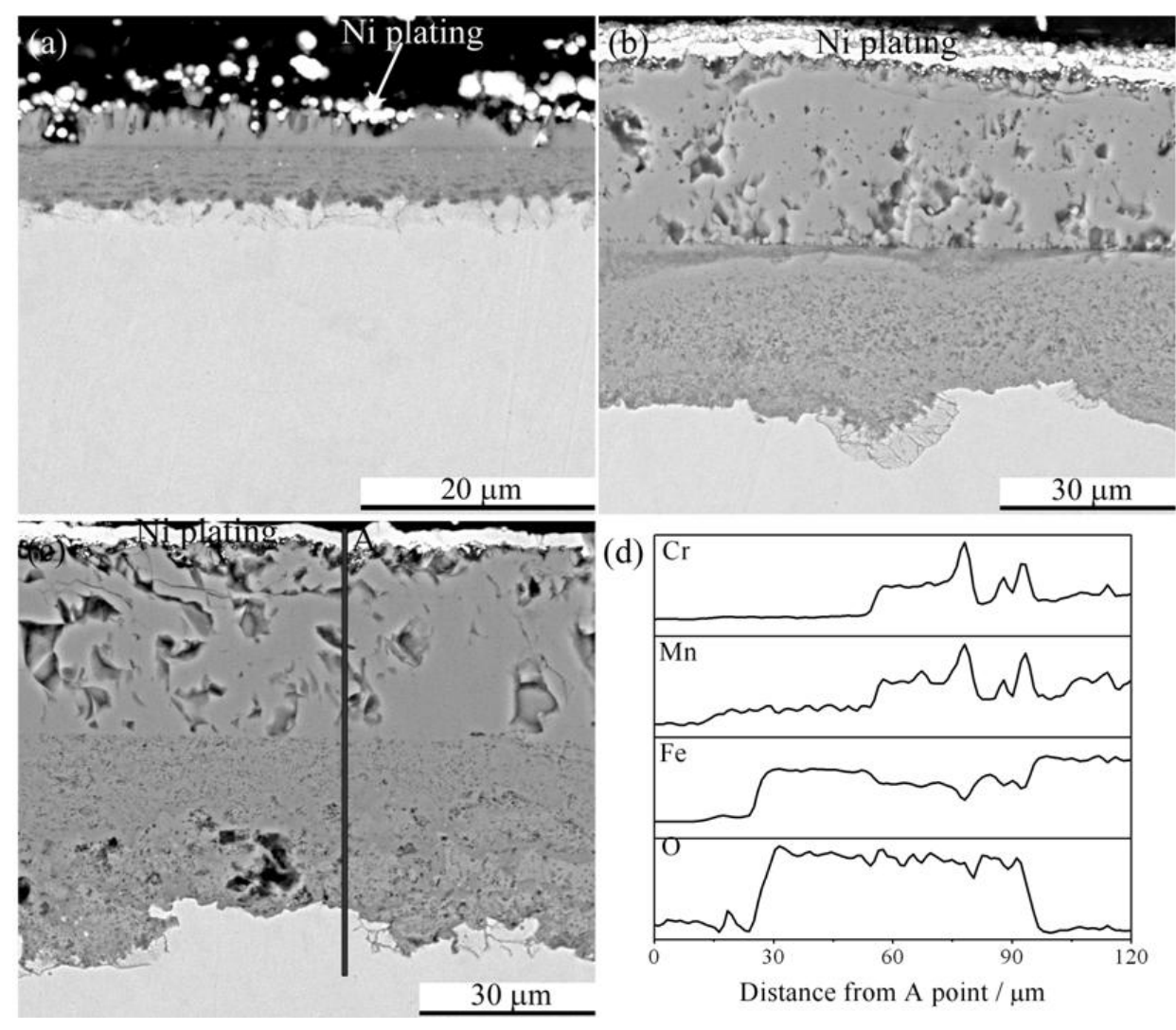

(d) $\mathrm{C}$

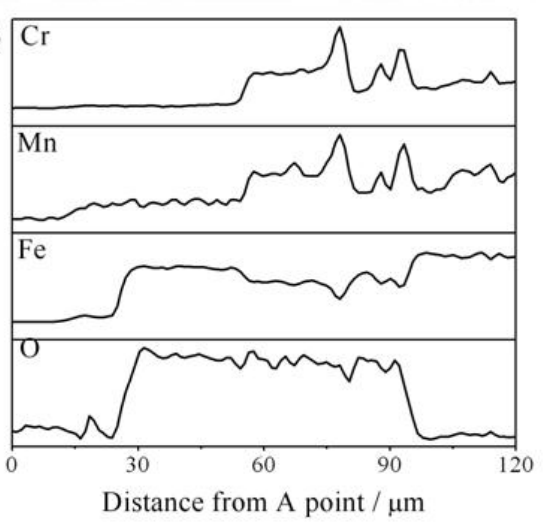

Figure 9. (a) Oxidation kinetics and (b) parabolic fitting of P92 in two-stage exposures at $700{ }^{\circ} \mathrm{C}$.
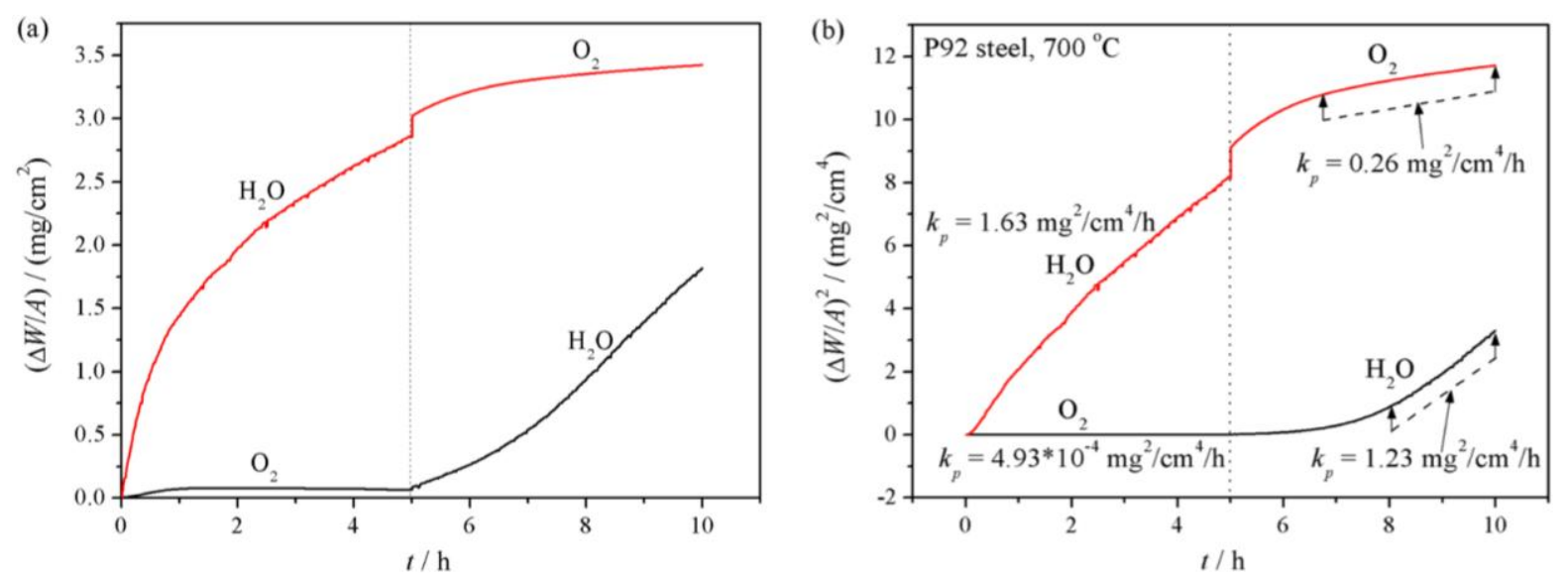
After two-stage oxidation, the appearances of oxidized specimens in two cases were rather different. Dark red and gray oxides can be seen on the specimen oxidized in the " $\mathrm{O}_{2}$ then $\mathrm{H}_{2} \mathrm{O}$ " case (Figure 10a), while the specimen oxidized in the " $\mathrm{H}_{2} \mathrm{O}$ then $\mathrm{O}_{2}$ " case was wholly covered by dark red oxides (Figure 10b).

Figure 10. Macroscopical appearance of oxidized $\mathrm{P} 92$ specimens after two-stage exposure at $700{ }^{\circ} \mathrm{C}$ : (a) $\mathrm{O}_{2}$ then $\mathrm{H}_{2} \mathrm{O}$; and (b) $\mathrm{H}_{2} \mathrm{O}$ then $\mathrm{O}_{2}$.
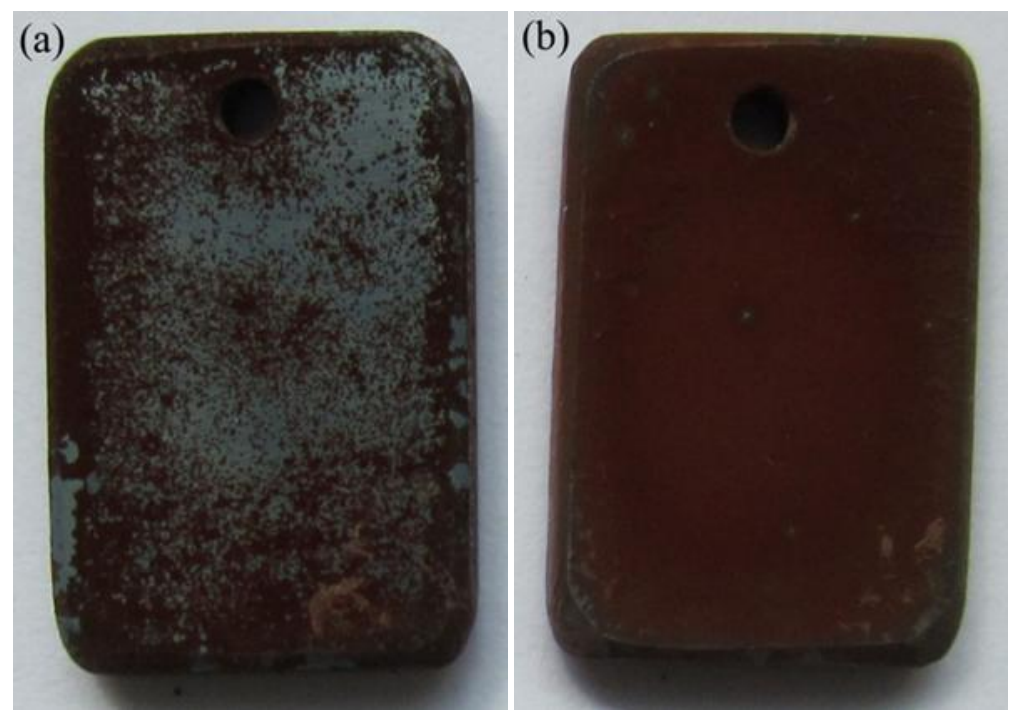

According to the oxidation kinetics, it can be speculated that the scale grown in the first-stage exposure in oxygen was mainly composed of thin protective $(\mathrm{Fe}, \mathrm{Cr})_{2} \mathrm{O}_{3}$ layer, the subsequent exposure in pure steam significantly enhanced the oxidation by prompting the formation of non-protective Fe-rich oxides. The $\mathrm{OM}$ images of the specimen after exposure in the " $\mathrm{O}_{2}$ then $\mathrm{H}_{2} \mathrm{O}$ " case is present in Figure 11a, it is evident that large oxide nodules with three-layer structure were embedded in the thin protective scale. At the edge of the specimen, thin protective scale disappeared. EDS line scan through the large oxide nodule indicated that the outer protruding layer was iron oxides, while the crater layer was $(\mathrm{Fe}, \mathrm{Cr}, \mathrm{Mn})$ oxides. It is reasonable to infer that the three layers are hematite, magnetite, and (Fe,Cr,Mn) oxides form the oxide/gas interface to the oxide/steel interface. In addition, some amount of internal $\mathrm{Cr}$ oxides with dark contrast exists at the oxide/steel interface.

Figure 11. Optical Microscopy (OM) cross section images of $\mathrm{P} 92$ after two-stage exposure at $700{ }^{\circ} \mathrm{C}$ : (a) $\mathrm{O}_{2}$ then $\mathrm{H}_{2} \mathrm{O}$; and (b) $\mathrm{H}_{2} \mathrm{O}$ then $\mathrm{O}_{2}$.

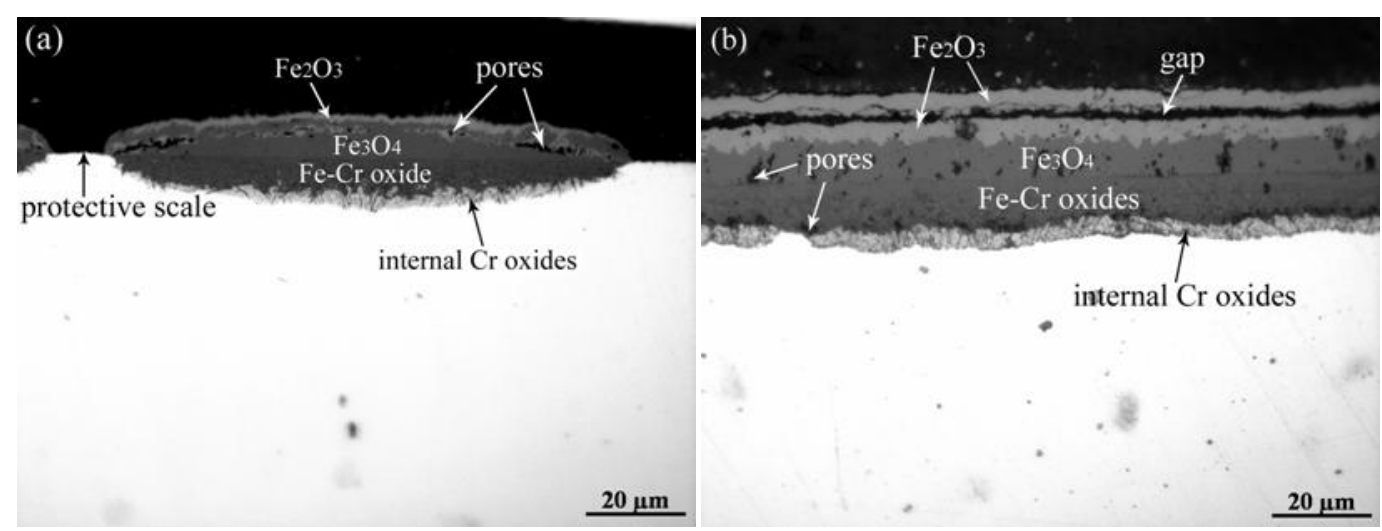


After oxidation in pure steam, double-layer scale with an outer Fe oxide layer and an inner (Fe,Cr,Mn) oxide layer was found, similar to the observation mentioned in Section 2.2. The subsequent exposure in oxygen reduced the oxidation rate to a great extent and led to a four-layer scale structure as shown in Figure 11b. Combined with EDS analysis, the outer layers with light gray contrast could be considered as hematite, the sub-scale with relatively dark gray contrast as magnetite, and the inner layer with the darkest contrast as ( $\mathrm{Fe}, \mathrm{Cr}, \mathrm{Mn})$ oxides. The hematite layer is separated into two layers by a continuous gap. It is worth noting that the thickness of hematite layer is slightly greater than the magnetite layer.

\section{Discussion}

Based on the experimental results, it could be found that oxidation behavior of P92 was significantly dependent on the oxidizing gas and temperature in short-term exposure. It also indicated that pure steam increased the critical chromium content required to form continuous external chromia scale, consequently prompted the formation of iron oxides and internal $\mathrm{Cr}$ oxides.

For the oxidation $\mathrm{Fe}-\mathrm{Cr}$ alloys, the affinity of metal element to oxygen determines the stability of its oxide. According to $\Delta \mathrm{G}^{\mathrm{o}}-T$ diagram [12], $\mathrm{Cr}_{2} \mathrm{O}_{3}$ is much more stable than iron oxides including $\mathrm{Fe}_{2} \mathrm{O}_{3}$, $\mathrm{Fe}_{3} \mathrm{O}_{4}$ and $\mathrm{FeO}$. For the oxidation of metal, the thermodynamic stability of its oxides would reveal the possibility of reaction, but would not determine the reaction kinetics. During the initial oxidation of $\mathrm{Fe}-\mathrm{Cr}$ alloys, $\mathrm{Fe}$ and $\mathrm{Cr}$ on the specimen surface would be oxidized simultaneously, so that the oxide scale would be determined by the relative oxidation rate of $\mathrm{Fe}$ and $\mathrm{Cr}$. Here, the oxidation rate contains the concentration of reactant and transport parameters. For a $\mathrm{Fe}-\mathrm{Cr}$ alloy with given chromium content, once the relative oxidation rate of $\mathrm{Cr}$ is faster, $\mathrm{Cr}$ would be oxidized selectively.

Oxidation of pure metals considered as extreme conditions will be discussed. In order to avoid the influence of carrier gas on the oxidation process, only the cases whereby inert gases were used as carrier gases are considered. Reviewing the published literatures, it can be found that the presence of water vapor remarkably accelerates the oxidation of iron [14,15], reduces the oxidation of nickel [16,17], and slightly increases [18] or does not affect the oxidation of chromium [19]. From this perspective, it can be speculated that water vapor would lower the relative oxidation rate of $\mathrm{Cr}$ in $\mathrm{Fe}-\mathrm{Cr}$ alloys while improve the relative oxidation rate of $\mathrm{Cr}$ in $\mathrm{Ni}-\mathrm{Cr}$ alloys. In consequence, the selective oxidation of chromium in water vapor would be suppressed in $\mathrm{Fe}-\mathrm{Cr}$ alloys while prompted in $\mathrm{Ni}-\mathrm{Cr}$ alloys. In other words, the critical chromium content in $\mathrm{Fe}-\mathrm{Cr}$ alloys required to form protective chromia scale would increase in water vapor containing gases, as observed in many works [17,20,21]. Essuman et al. [22] also considered that water vapor enhanced the internal oxidation of $\mathrm{Cr}$ in $\mathrm{Fe}-\mathrm{Cr}$ alloys, possibly due to the result of water vapor affecting the solubility and/or the diffusivity of oxygen in the alloy.

In the two-stage cases, the oxidation behavior of P92 was significantly influenced by the gas switch. After a slower scale-growing process in oxygen, the introduction of steam sharply increased the scaling rate and markedly transformed the protective scale formed in oxygen to non-protective iron-rich oxides. The breakaway of protective scale might be induced by the hydrogen effects generated in the oxidation process in steam [4]. Once the chromium concentration at the scale/steel interface cannot heal the breakdown of protective scale, the outward transport of iron ions and inward diffusing of hydroxyl ions would be prompted. In the " $\mathrm{H}_{2} \mathrm{O}$ then $\mathrm{O}_{2}$ " case, multilayer oxide scales with an outer iron oxides layer grew rapidly in the first-stage exposure, and acted as a barrier for the diffusing species in the 
second-stage exposure. Herein, the scaling rate in the second-stage exposure (oxygen) would be controlled by the diffusion process. The thickening of the outer hematite layer and the much lower scaling rate may indicate that the inward transport of oxygen is important [11] and its diffusing ability is much slower than hydroxyl species in steam.

\section{Experimental}

Commercial ferritic/martensitic P92 was used in the present work and its chemical composition is Fe-0.1C-0.5Si-0.5Mn-0.4Ni-9.5Cr-0.6Mo-0.1Nb-0.3Cu-2W (in weight percent). $\mathrm{P} 92$ tube as received was cut into coupons with dimensions of $10 \times 15 \times 2 \mathrm{~mm}^{3}$. All the coupons were ground to $1000 \#$ with $\mathrm{SiC}$ papers, and cleaned ultra-sonically by distilled water and ethanol for $15 \mathrm{~min}$ in subsequence.

Isothermal oxidation experiments in the range of $600-800{ }^{\circ} \mathrm{C}$ were conducted in a TGA system (Thermo Fisher Scientific, Karlsruhe, Germany) where steam or oxygen could be introduced [14]. Flowing steam was generated by pumping ultra-purified water (resistivity is greater than $10 \mathrm{M} \Omega \cdot \mathrm{cm}$ ) containing 7-9 ppm (wt\%) dissolved oxygen into pre-heater at the flow rate $1 \mathrm{~mL} / \mathrm{min}$. The purity of oxygen is greater than $99.995 \%$. Two-stage oxidation tests denoted as " $\mathrm{O}_{2}$ then $\mathrm{H}_{2} \mathrm{O}$ " and " $\mathrm{H}_{2} \mathrm{O}$ then $\mathrm{O}_{2}$ " were also performed in the TGA system where oxidation temperature was maintained at $700{ }^{\circ} \mathrm{C}$. Between the two stages, high purity argon was flowed to purge the oxidizing gas in the first stage. For each stage, $5 \mathrm{~h}$ exposure was used. In all cases, the heating and cooling rate are $80{ }^{\circ} \mathrm{C} / \mathrm{min}$ and $-5^{\circ} \mathrm{C} / \mathrm{min}$ respectively.

The oxidized specimens were characterized carefully in terms of scale microstructure and phase composition. Scale microstructures were investigated by OM (Zeiss, Jena, Germany) and SEM (FEI, Hillsboro, TX, USA). Oxide phases were identified by XRD (PANalytical, Almelo, The Netherlands). The outmost surface oxides formed in steam and the thin oxide scales formed in oxygen were analyzed by Grazing Incidence XRD (GIXRD) with an incidence angle of $0.5^{\circ}$.

\section{Conclusions}

Based on the experimental results, it can be concluded that:

(1) Within the studied temperature range, the scaling rates of P92 in pure steam were significantly increased compared to those in pure oxygen. Accordingly, non-protective oxide scales composed of an outer iron oxide layer (including hematite and magnetite), a middle $\mathrm{Fe}-\mathrm{Cr}$ oxides layer and internal $\mathrm{Cr}$-rich oxides formed in pure steam rather than more protective scales in pure oxygen. It is considered that the enhanced oxidation in pure steam was attributed to the higher affinity of iron to steam which resulted in the increase of critical chromium concentration in $\mathrm{Fe}-\mathrm{Cr}$ alloys required to form protective chromia scale;

(2) Two-stage exposure at $700{ }^{\circ} \mathrm{C}$ showed a significant influence of gas switch on the scaling kinetics and scale microstructure of P92. It can be speculated that the breakaway of the initial protective oxide scale would be resulted from the hydrogen effect. Although the inward transport of anions through multilayer oxide scales was important in both environments, the migration of hydroxyl seemed much easier. 


\section{Acknowledgements}

The authors are grateful for the financial supports from the National Nature Science Foundation of China under Contracts of 51071163 and the National Key Basic Research Program of China (973 Program) under grant No. 2012CB625100.

\section{Author Contributions}

The tests were carried out by Juntao Yuan and Ximao Wu, characterization was performed by Wen Wang and Shenglong Zhu, the experimental scheme was framed Fuhui Wang. The manuscript was composed by Juntao Yuan and revised by Wen Wang.

\section{Conflicts of Interest}

The authors declare no conflict of interest.

\section{References}

1. Saunders, S.R.J.; Monteiro, M.; Rizzo, F. The oxidation behaviour of metals and alloys at high temperatures in atmospheres containing water vapour: A review. Prog. Mater Sci. 2008, 53, 775-837.

2. Halvarsson, M.; Tang, J.E.; Asteman, H.; Svensson, J.E.; Johansson, L.G. Microstructural investigation of the breakdown of the protective oxide scale on 304 steel in the presence of oxygen and water vapour at $600{ }^{\circ} \mathrm{C}$. Corros. Sci. 2006, 48, 2014-2035.

3. Asteman, H.; Svensson, J.E.; Johansson, L.G. Oxidation of 310 steel in $\mathrm{H}_{2} \mathrm{O}-\mathrm{O}_{2}$ mixtures at $600{ }^{\circ} \mathrm{C}$ : The effect of water-vapour-enhanced chromium evaporation. Corros. Sci. 2002, 44 , 2635-2649.

4. Shen, J.; Zhou, L.; Li, T. High-temperature oxidation of Fe-Cr alloys in wet oxygen. Oxid. Met. 1997, 48, 347-356.

5. Asteman, H.; Svensson, J.E.; Johansson, L.G. Evidence for Chromium Evaporation Influencing the Oxidation of 304L: The Effect of Temperature and Flow Rate. Oxid. Met. 2002, 57, 193-216.

6. Peng, X.; Yan, J.; Zhou, Y.; Wang, F. Effect of grain refinement on the resistance of 304 stainless steel to breakaway oxidation in wet air. Acta Mater. 2005, 53, 5079-5088.

7. Young, D.J.; Pint, B.A. Chromium volatilization rates from $\mathrm{Cr}_{2} \mathrm{O}_{3}$ scales into flowing gases containing water vapor. Oxid. Met. 2006, 66, 137-153.

8. Othman, N.K.; Zhang, J.; Young, D.J. Temperature and water vapour effects on the cyclic oxidation behaviour of Fe-Cr alloys. Corros. Sci. 2010, 52, 2827-2836.

9. Opila, E.J.; Myers, D.L.; Jacobson, N.S.; Nielsen, I.M.B.; Johnson, D.F.; Olminsky, J.K.; Allendorf, M.D. Theoretical and Experimental Investigation of the Thermochemistry of $\mathrm{CrO}_{2}(\mathrm{OH})_{2}(\mathrm{~g}) . J$. Phys. Chem. A 2007, 111, 1971-1980.

10. Yuan, J.; Wu, X.; Wang, W.; Zhu, S.; Wang, F. The Effect of Surface Finish on the Scaling Behavior of Stainless Steel in Steam and Supercritical Water. Oxid. Met. 2013, 79, 541-551. 
11. Ehlers, J.; Young, D.J.; Smaardijk, E.J.; Tyagi, A.K.; Penkalla, H.J.; Singheiser, L.; Quadakkers, W.J. Enhanced oxidation of the $9 \% \mathrm{Cr}$ steel P91 in water vapour containing environments. Corros. Sci. 2006, 48, 3428-3454.

12. Birks, N.; Meier, G.H.; Pettit, F.S. Introduction to the High Temperature Oxidation of Metals, 2nd ed.; Cambridge University Press: New York, NY, USA, 2006.

13. Zhang, D.; Xu, J.; Zhao, G.; Guan, Y.; Li, M. Oxidation characteristic of ferritic-martensitic steel T91 in water-vapour atmosphere. Chin. J. Mater. Res. 2008, 22, 599-605.

14. Yuan, J.; Wang, W.; Zhu, S.; Wang, F. Comparison between the oxidation of iron in oxygen and in steam at $650-750{ }^{\circ}$ C. Corros. Sci. 2013, 75, 309-317.

15. Nakai, M.; Nagai, K.; Murata, Y.; Morinaga, M.; Matsuda, S.; Kanno, M. Correlation of high-temperature steam oxidation with hydrogen dissolution in pure iron and ternary high-chromium ferritic steel. ISI J. Int. 2005, 45, 1066-1072.

16. Auchi, M.; Hayashi, S.; Toyota, K.; Ukai, S. Effect of Water Vapor on the High-Temperature Oxidation of Pure Ni. Oxid. Met. 2012, 78, 51-61.

17. Essuman, E.; Meier, G.H.; Zurek, J.; Hänsel, M.; Norby, T.; Singheiser, L.; Quadakkers, W.J. Protective and non-protective scale formation of $\mathrm{NiCr}$ alloys in water vapour containing high- and low-pO2 gases. Corros. Sci. 2008, 50, 1753-1760.

18. Jacob, Y.P.; Haanappel, V.A.C.; Stroosnijder, M.F.; Buscail, H.; Fielitz, P.; Borchardt, G. The effect of gas composition on the isothermal oxidation behaviour of PM chromium. Corros. Sci. 2002, 44 , 2027-2039.

19. Hansel, M.; Quadakkers, W.J.; Young, D.J. Role of Water Vapor in Chromia-Scale Growth at Low Oxygen Partial Pressure. Oxid. Met. 2003, 59, 285-301.

20. Essuman, E.; Meier, G.H.; Zurek, J.; Hansel, M.; Quadakkers, W.J. The Effect of Water Vapor on Selective Oxidation of Fe-Cr Alloys. Oxid. Met. 2008, 69, 143-162.

21. Othman, N.K.; Othman, N.; Zhang, J.; Young, D.J. Effects of water vapour on isothermal oxidation of chromia-forming alloys in $\mathrm{Ar} / \mathrm{O}_{2}$ and $\mathrm{Ar} / \mathrm{H}_{2}$ atmospheres. Corros. Sci. 2009, 51, 3039-3049.

22. Essuman, E.; Meier, G.H.; Zurek, J.; Hansel, M.; Singheiser, L.; Quadakkers, W.J. Enhanced internal oxidation as trigger for breakaway oxidation of $\mathrm{Fe}-\mathrm{Cr}$ alloys in gases containing water vapor. Scr. Mater. 2007, 57, 845-848.

(C) 2014 by the authors; licensee MDPI, Basel, Switzerland. This article is an open access article distributed under the terms and conditions of the Creative Commons Attribution license (http://creativecommons.org/licenses/by/3.0/). 